\section{Cooperação internacional e políticas de ação afirmativa: o papel da Organização Pan-Americana da Saúde (OPAS)}

\author{
International cooperation and affirmative action \\ policies: the role of the Pan American Health \\ Organization (PAHO)
}

\author{
${ }_{1}$ Casa de Oswaldo Cruz, \\ Fundação Oswaldo Cruz, Rio \\ de Janeiro, Brasil. \\ 2 Observatório História e \\ Saúde, Fundação Oswaldo \\ Cruz/Ministério da Saúdel \\ Organização Pan-Americana \\ da Saúde, Rio de Janeiro, \\ Brasil. \\ Correspondência \\ M. C. Maio \\ Casa de Oswaldo Cruz, \\ Fundação Oswaldo Cruz. \\ Av. Brasil 4036, sala 400, Rio \\ de Janeiro, RJ 21410-361. \\ Brasil. \\ maio@coc.fiocruz.br
}

Abstract

The article analyzes the formulation, legitimation, and implementation of a policy with an ethnic/race approach by the Pan American Health Organization (PAHO). The study includes the emergence of the theme within this international organization, the institutional dynamics related to it, and the proposals focused on the Black population in Latin America. These issues are discussed on the basis of interaction between PAHO and a range of intergovernmental agencies and private organizations working in the international health domain. Participation by PAHO in the ethnic/racial theme provides elements for understanding the dual role played by intergovernmental organizations in the new global scenario, as both social actors and arenas. As an important social actor in the international health field, PAHO has produced and disseminated values and guidelines related to the ethnic/ racial theme. As an arena, the organization has proven open to various interests, seeking to work harmoniously with them through its internal administration.

Pan American Health Organization; International Agencies; International Cooperation; Ethnic Groups
Marcos Chor Maio 1

Fernando A. Pires-Alves 1,2

Carlos Henrique Assunção Paiva 1,2

Rodrigo Cesar da Silva Magalhães 1

\section{Introdução}

Este trabalho tem por objetivo analisar, no âmbito da Organização Pan-Americana da Saúde (OPAS), a gênese de uma política de ação afirmativa no terreno da saúde da população negra. O estudo compreende o processo de emergência do tema no interior da Organização, a dinâmica institucional que gradativamente impulsiona um movimento na instituição sobre a necessidade de políticas voltadas para esses grupos populacionais específicos e as interações estabelecidas entre a OPAS e um conjunto de agências intergovernamentais e organizações privadas com atuação relevante no domínio da saúde internacional.

$\mathrm{Na}$ primeira parte do artigo explicita-se a abordagem adotada na análise de uma organização internacional de saúde e das suas relações com os Estados nacionais, com outras organizações intergovernamentais, comunidades especializadas e entidades da sociedade civil. As seções seguintes comentam as primeiras manifestações da temática étnico-racial na OPAS e os seus desdobramentos, em especial a partir dos episódios da preparação da III Conferência Mundial das Nações Unidas contra o Racismo, realizada na cidade sul-africana de Durban em 2001. Seguem-se as conclusões em que é discutida a complexidade do ambiente institucional no qual ocorreram a formulação e as decisões em torno de uma política regional em etnicidade e saúde, caracterizada pela presença de novos atores, com 
significativo poder de expressão. Considera-se, ainda, de que maneira esse processo foi influenciado pela experiência anterior da OPAS no terreno da saúde das populações indígenas, e como a institucionalização desta experiência moldou ou constrangeu as possibilidades institucionais da nova agenda.

\section{Organizações intergovernamentais, Estado e a agenda da saúde internacional}

Organizações intergovernamentais (OIs) são consideradas neste texto, simultaneamente, como atores sociais e arenas. Como atores, de um lado, são capazes de produzir realidades, seja pela ação institucional direta, seja pela produção e disseminação de valores, normas e modelos de conduta 1 . De outro lado, OIs são também arenas, na medida em que se mostram permeáveis à expressão de interesses de origens diversas. São arenas, ainda, porque os eventuais interesses de suas burocracias internas também se manifestam em um ambiente concorrencial, com a adoção de estratégias de convencimento e legitimação.

Como ator e arena, uma OI de tipo funcional ou setorial 2, como a OPAS, orientada para ação em um domínio específico de problemas, se configura como parte integrante de um ambiente institucional e normativo mais amplo, nos marcos do que se configuram como referenciais institucionais globais ${ }^{3}$. No nosso caso específico, desde o início dos anos 1980, no âmbito da cooperação técnica internacional, esse ambiente pode ser caracterizado como de crise do desenvolvimento, percebida como uma modificação significativa das relações mantidas entre países do mundo dito desenvolvido e os demais, tal como foram até então experimentados desde o final da Segunda Guerra Mundial 4.

Constitui parte dessa crise o fato de que o Estado gradativamente viu reduzido o seu papel de protagonista privilegiado na organização da vida social e do processo de desenvolvimento, ao mesmo tempo em que se registrava a emergência de atores não-estatais cada vez mais influentes. Articula-se a esse processo a perda de autonomia e importância das OIs nas quais para cada país membro corresponde um voto em seus fóruns deliberativos, frente àquelas, como o Banco Mundial e o Banco Interamericano de Desenvolvimento (BID), em que prevalece o voto dos principais países mantenedores. $\mathrm{O}$ aumento da importância relativa dessas agências e de organizações privadas de cunho filantrópico, que ocorreu também no âmbito da saúde, contribuiu para o fortalecimento das orientações que ten- diam a promover o papel da iniciativa privada e de suas organizações na condução de programas e na prestação direta de serviços à população 5 .

Essa nova realidade implicou um enfraquecimento relativo da Organização Mundial da Saúde (OMS) no domínio da saúde internacional, enfraquecimento este que atingiu também suas organizações regionais, dentre as quais a OPAS. Essa fragilidade expressava-se sob a forma de um orçamento cada vez mais dependente dos chamados fundos extra-orçamentários, resultantes de contribuições de agências como o Banco Mundial e de doações de fundações privadas, tais como as fundações Bill \& Melinda Gates, Rockefeller e Ford. Assim, países doadores ricos, o Banco Mundial e fundações privadas eram capazes de definir sua própria política no interior da programação da OMS com considerável autonomia frente às decisões da Assembléia Mundial da Saúde. Essas orientações, mais uma vez, tendiam a promover o surgimento e a patrocinar uma constelação de novas organizações não-governamentais na condução dos programas, em detrimento dos sistemas nacionais de saúde e das agências estatais, consideradas ineficazes 5,6.

Essa trajetória de perda relativa de importância da OMS e de fragilização de suas instâncias políticas ocorreu em sincronia e íntima relação com o conflito que na saúde internacional opunha a concepção de "Atenção Primária Integral à Saúde", tal como aprovada na Conferência de Alma Ata, de 1978, àquela de "Atenção Primária Seletiva”. Esta última, patrocinada pela Agência Norte-Americana de Desenvolvimento Internacional (USAID), o Banco Mundial, a Fundação Rockefeller, e experimentada também pelo Fundo das Nações Unidas para a Infância (UNICEF) a partir de 1980, propunha soluções estritamente pragmáticas, de caráter focal e baixo custo técnico, orientada mais para resultados imediatos do que para transformações estruturais no terreno da saúde pública e que, mais uma vez, pugnava por uma maior presença de entidades privadas na prestação de serviços ${ }^{5}$. Assim, essa crise da OMS era, ela mesma, expressão de uma confrontação doutrinária acerca da saúde, sobre qual o papel e as responsabilidades do Estado na prestação e financiamento de serviços, sobre a atenção focalizada ou universal.

Há que considerar, ainda, que a OPAS possui uma história institucional própria no terreno específico das relações entre etnicidade e saúde, especialmente no tocante à saúde das populações indígenas. Portanto, a emergência mais recente das questões das relações entre etnia e saúde e, em particular, da saúde da população negra, ocorreu em um ambiente político-institucional que, pelo menos desde meados do século XX, já 
era freqüentado pela associação entre saúde comunitária e populações indígenas, em especial nos contextos andino e centro-americano. $\mathrm{Ou}$ seja, o advento da nova orientação ocorreu na vigência de políticas pretéritas em áreas correlatas, políticas estas que configuravam uma determinada trajetória institucional 7 .

A gênese de uma política compartilhada entre a OPAS e o Estado brasileiro no terreno das ações afirmativas de corte racial deve ser contextualizada também pela emergência de uma nova diretriz para as relações exteriores brasileiras. A partir da década de 1990, o Brasil adotou gradualmente uma agenda de política externa mais orientada pela lógica da autonomia pela integração, procurando, assim, se posicionar de forma mais pró-ativa frente aos acontecimentos mundiais 8 .

Nesse enquadramento contextual, a arena decisória acerca das políticas e dos programas internacionais de saúde tornou-se povoada por novos atores e grupos de interesse, ao mesmo tempo em que a agenda revelava-se crescentemente relevante para os interesses estratégicos do Estado e, simultaneamente, aos processos de formação da opinião pública. O alargamento na composição da arena decisória, dos meios de pressão mobilizados nos debates e do número de organizações envolvidas no processo de execução de programas alia-se a uma nova percepção acerca dos graus de interdependência nos fenômenos da saúde 5 .

As relações entre etnia e saúde, em especial no tocante à saúde da população negra, tornaramse, assim, ponto de pauta da OPAS, assim como do governo brasileiro em meio a essa nova configuração institucional e ao debate doutrinário em torno da oposição universalização/focalização. Examinar o seu contexto de surgimento no âmbito da OPAS significa ter de considerar de que maneira aquela configuração e este debate ocorriam especificamente na região das Américas.

\section{A articulação inicial em torno do combate ao racismo e à pobreza}

A emergência de uma agenda voltada para as populações mestiças e negras das Américas ocorreu em meio aos processos de democratização das sociedades latino-americanas nos anos 1980/1990. Simultaneamente, recebeu impulso adicional dos desdobramentos de algumas conferências da Organização das Nações Unidas (ONU) ocorridas na década de 1990, como a Cúpula Mundial sobre Meio Ambiente e Desenvolvimento, celebrada no Rio de Janeiro, Brasil, em 1992; a Conferência Internacional sobre População e Desenvolvimento, realizada no Cairo, Egito, em 1994; a Conferência Mundial sobre a Mulher, em Pequim, China, em 1995; entre outras. Contando com a participação de agências multilaterais e organismos financeiros internacionais, essas conferências teriam contribuído para aprofundar temas como os direitos humanos e a pobreza 9,10.

Algumas análises enfatizam, em especial, o papel desempenhado pelo processo preparatório para a III Conferência Mundial das Nações Unidas Contra o Racismo, a Discriminação Racial, a Xenofobia e Formas Correlatas de Intolerância - realizada na cidade sul-africana de Durban, em 2001 - na qual teria se conformado o que Mala Htun 11 qualifica de redes transnacionais de advocacy, compostas por atores relevantes trabalhando internacionalmente sobre uma determinada questão que, de posse de um discurso e valores comuns, procuram alterar o comportamento dos Estados e das organizações internacionais por meio de um intenso intercâmbio de informações e serviços. Assim, foi nessas reuniões preparatórias que se definiu a própria agenda temática da conferência 6 .

Esse processo preparatório recebe o influxo, ao mesmo tempo em que é catalisador de uma crescente atenção para a relação entre racismo e pobreza. Como parte desse movimento, o Banco Mundial, o BID e o Inter-American Dialogue organizaram em Washington DC, Estados Unidos, em junho de 2000, a conferência Race and Poverty: Interagency Consultation on Afro-Latin Americans. Reunindo fundações internacionais, governos, organizações não-governamentais e do movimento negro, líderes e analistas proeminentes das comunidades afro-latino-americanas tiveram como objetivo central explorar, dentro e fora dessas organizações, as conexões entre raça e exclusão social, política e econômica. Na conferência, essa questão foi abordada com base nos seguintes eixos: (a) a forma pela qual as leis afetam os direitos dos afro-latino-americanos em alguns países; (b) o papel da sociedade civil e de grupos de pressão que trabalham sobre questões relacionadas aos afro-latinos; (c) raça e etnicidade como fatores importantes na política da América Latina; e (d) questões-chave de pesquisa que tenham como objeto pobreza e raça 12.

O final do encontro foi marcado pela decisão conjunta das instituições promotoras de criar, com o apoio da Fundação Ford, a Inter-Agency Consultation on Race and Poverty in Latin America (IAC) que, segundo o Presidente do InterAmerican Dialogue, Peter Hakim, deveria se constituir em um mecanismo permanente para ajudar os quatro organismos a melhor entender e identificar os problemas específicos dos latinoamericanos descendentes de africanos, dentre os 
quais a discriminação racial, os elevados índices de pobreza e analfabetismo e o acesso limitado à educação, saúde e demais serviços públicos 12 .

A realização da conferência Race and Poverty e a criação do IAC constituem-se em evidências de um aumento da importância conferida às desigualdades raciais para as análises sobre as causas da pobreza. Ambas contribuíram para a disseminação da crença de que as políticas antipobreza poderiam ser mais efetivas se conjugadas com estratégias antidiscriminação. Essa nova orientação passaria a nortear a atuação de fundações e organismos internacionais em relação à questão racial, dentre as quais a OPAS.

\section{A emergência da temática étnico-racial na OPAS}

A OPAS começou a se envolver com a temática da saúde da população negra durante o processo preparatório para a conferência de Durban em fins da década de 1990. Por essa ocasião, a Organização já tinha uma tradição institucionalizada no desenvolvimento de políticas voltadas para a população indígena, tradição esta que vem sendo reafirmada periodicamente. Em 1992, por exemplo, o Subcomitê de Planejamento e Programa, do Comitê Executivo da OPAS, propôs que se considerasse mais cuidadosamente a saúde e o bem-estar das populações indígenas das Américas. Em resposta a essa recomendação, no ano seguinte - definido pela ONU como o ano dos povos indígenas - a OPAS patrocinou um workshop sobre povos indígenas e saúde que resultou na aprovação de uma recomendação e na elaboração de um Plano de Ação 13.

A tradição da OPAS no campo da saúde da população indígena revela que a adoção de políticas com enfoque étnico não era uma novidade para a Organização. O termo etnia era, até então, constantemente empregado em seus documentos e publicações em referência às populações indígenas, sem qualquer menção aos contingentes negros. Essa situação começou a mudar a partir da realização da Conferência Regional Preparatória para a Conferência Mundial contra o Racismo, realizada em Santiago, Chile, em dezembro de 2000. Nessa ocasião, aprovou-se a proposta apresentada pela delegação brasileira, recomendando à OPAS a adoção de ações visando ao reconhecimento das variáveis raça, etnia e gênero no campo da saúde, e que desenvolvesse projetos específicos para a população negra 14 . A partir desse momento, a OPAS começaria a envolver-se cada vez mais com essa temática.

A conferência de Santiago representou, para o contexto latino-americano, a primeira mani- festação da nova orientação que procurava articular a luta antipobreza no continente com políticas anti-racismo. Muitos itens da Declaração e do Plano de Ação firmados nessa ocasião destacavam a acentuada situação de pobreza em que se encontravam os povos indígenas e as populações de ascendência africana e preconizavam políticas a serem adotadas em benefício destes grupos 14 . As populações negras e indígenas foram colocadas em pé de igualdade como vítimas de discriminação racial e como alvos prioritários. Foi, portanto, no quadro dessa situação relativamente nova no cenário latino-americano que a OPAS foi demandada a adotar políticas específicas de recorte racial.

Logo após a conferência de Santiago, a socióloga Cristina Torres, então consultora do Programa de Políticas Públicas e Saúde (PPPS) da Divisão de Saúde e Desenvolvimento Humano da OPAS, publicou artigos que enfocavam as relações entre etnicidade e saúde, com destaque para a situação dos grupos negros. Na sua opinião, a redução da pobreza nas Américas - parte fundamental da agenda política do desenvolvimento - não se resume apenas a corrigir tratamentos desiguais no mercado de trabalho, mas sim à redução das assimetrias no acesso aos serviços de educação, saúde e representação política ${ }^{15}$. Em acordo com essa posição, o médico César Vieira, integrante da equipe do PPPS, destacou que a incorporação das perspectivas de etnicidade nas atividades de cooperação da Divisão de Saúde e Desenvolvimento Humano da OPAS estava relacionada à analise das iniqüidades de saúde, entendidas como diferenças injustificadas e injustas entre os grupos 16 .

Nesse mesmo contexto, em junho de 2001, realizou-se em Washington DC a Reunião do Grupo de Especialistas em Etnicidade e Eqüidade em Saúde, organizada pela OPAS, BID, InterAmerican Dialogue e Banco Mundial. Com base nas discussões travadas nessa reunião, a OPAS elaborou um Plano de Ação sobre Etnicidade e Eqüidade em Saúde, cujo objetivo geral era colaborar com os países na criação de uma política de saúde sensível à variável étnica 17 .

As atividades propostas passavam pelo desenvolvimento de planos, programas e políticas de saúde, coleta e análise de dados, treinamento de recursos humanos e advocacy. Incluíam também a mobilização de recursos financeiros, por meio dos quais se procurava responder às demandas dos países latino-americanos por políticas de saúde que levassem em conta a variável étnica. Com o Plano de Ação, a OPAS, pela primeira vez, buscava enfrentar no terreno prático a discriminação racial contra os negros como um obstáculo ao acesso a serviços, à informação e ao 
tratamento eqüitativo. Evidenciou-se uma crescente articulação entre a OPAS e o BID, o Banco Mundial e o Inter-American Dialogue, da qual é testemunho, por exemplo, a realização do encontro Towards a Shared Vision of Development: High Level Dialogue on Race, Ethnicity, and Inclusion in Latin America and the Caribbean, promovido pelo BID, também na capital americana.

Paralelamente à articulação com os principais organismos financeiros internacionais, a OPAS, em conjunto com a OMS, lançou em abril de 2001 um novo documento de trabalho com o objetivo de fornecer subsídios para as discussões que se travariam na Conferência de Durban. Esse documento expressava a anuência de ambas as organizações com a adoção de uma nova perspectiva que procurava entender e reduzir os impactos das desigualdades étnico/raciais sobre a saúde 18 .

A análise dos artigos e documentos produzidos pela OPAS revela que muitas das questões neles abordadas foram definidas no encontro Race and Poverty, organizado pelo Banco Mundial, o BID e o Inter-American Dialogue no ano 2000. Essa sintonia é indicativa da capacidade dessas organizações de pautarem as discussões relacionadas à raça/etnia no âmbito internacional. Em um contexto no qual organismos como o Banco Mundial e o BID detinham um poder de agenda cada vez maior, a formulação de políticas de saúde com enfoque étnico-racial não poderia realizar-se à sua revelia.

\section{Os resultados de Durban e a agenda étnico-racial da OPAS}

Realizada entre 31 de agosto e 7 de setembro de 2001, a Conferência de Durban insere-se nos marcos da preocupação da ONU com o estabelecimento de um compromisso político em torno da eliminação de todas as formas de racismo, discriminação racial, xenofobia e intolerância correlata. Sua realização trouxe definitivamente para o primeiro plano as relações entre saúde e etnia, com ênfase na população negra. Dois documentos foram aprovados nessa ocasião - a Declaração e o Programa de Ação - ambos destacando as populações indígenas e negras como objeto privilegiado de preocupação. Neles reconhecia-se as contribuições culturais, econômicas, políticas e científicas dos afro-descendentes das Américas e, no campo da saúde, encorajava-se a OMS e outras organizações internacionais "a promover e desenvolver atividades para o reconhecimento do impacto do racismo, da discriminação racial, da xenofobia e de formas conexas de intolerância como determinantes sociais do status de saúde fi- sica e mental". O documento lembrava também o compromisso assumido por estas organizações com a Declaração do Milênio das Nações Unidas, que "propugnara pelo fortalecimento do respeito aos direitos humanos, inclusive os direitos das minorias, e pela tomada de medidas contra atos de racismo e xenofobia". Diante dessa recomendação, organizações como a OMS e a OPAS deveriam elaborar projetos específicos - que envolvessem, inclusive, pesquisas - com o objetivo de assegurar sistemas de saúde eqüitativos 19 .

A OPAS prontamente procurou atender a essas recomendações. Já em outubro de 2001 a Organização apoiou a realização da II Conferência Interparlamentar de Saúde, na Sede Permanente do Parlamento Latino-Americano, em São Paulo, ocasião em que Cristina Torres apresentou o trabalho Etnicidade e Saúde. Essa iniciativa também se expressava no âmbito das políticas nacionais de saúde. No Brasil, por exemplo, com a chancela do Programa das Nações Unidas para o Desenvolvimento (PNUD), a OPAS co-patrocinou a realização do Workshop Interagencial Saúde da População Negra. Nessa oportunidade, especialistas na temática étnico-racial reuniram-se em Brasília para propor subsídios para uma política nacional de saúde da população negra. As propostas apresentadas foram reunidas no documento Política Nacional de Saúde da População Negra: Uma Questão de Eqüidade 20,21,22.

A temática étnico-racial também passou a ter um maior destaque no debate programático da OPAS. No Plano Estratégico 2003-2007, a Organização priorizaria a promoção da saúde e a redução da mortalidade durante todo o ciclo de vida, sobretudo entre as "populações pobres e de baixa renda, grupos étnicos e raciais, especialmente as populações indigenas, as mulheres e as crianças (...) e outros grupos que experimentam desigualdades na saúde" 23 (p. 22-3). Na edição 2002 de Health in the Americas ${ }^{24}$, publicação da OPAS dedicada à análise da situação da saúde na região, no tópico Etnicidade e Saúde, identificamse dois atores fundamentais para a emergência de políticas públicas para populações específicas. Em primeiro lugar, as organizações nãogovernamentais indígenas e afro-americanas, cuja mobilização e poder de negociação com as agências governamentais foram destacados. O segundo grupo de atores mencionado era aquele formado por agências internacionais como o BID e o Banco Mundial, cujo trabalho de coleta de informações teria possibilitado o estabelecimento de redes de advocacy.

A publicação reconhece, ainda, que a origem étnica era uma variável até aquele momento desconsiderada na formulação de políticas voltadas para o desenvolvimento e a saúde, e constata que 
as disparidades entre populações não poderiam ser solucionadas pela introdução de políticas econômicas globais, mas sim por “(...) políticas seletivas (...) essenciais para corrigir as assimetrias que se acumularam ao longo dos anos como resultado de fatores culturais, políticos, religiosos, etc." 24 (p. 100).

O envolvimento da OPAS com a temática étnico-racial de fato ganhou impulso após a Conferência de Durban, cuja realização contou, segundo algumas análises, com a presença significativa de organizações latino-americanas e, em especial, do Brasil 6,11. O processo revelou também o protagonismo de organismos multilaterais, como o BID e o Banco Mundial, na emergência dessa temática. Registrou, da mesma forma, um ativo papel de organizações não-governamentais com acentuada participação no domínio das políticas sociais.

As evidências sugerem que pelo menos a OPAS parece ter desempenhado papel subordinado nesse processo genético. Os princípios e diretrizes adotados pela OPAS no terreno das políticas de ação afirmativa no tocante às populações negras indicam uma aproximação da Organização àquelas estratégias seletivas de saúde e de mobilização direta de grupos e comunidades organizados, tal como preconizadas pelo Banco Mundial e pelos grandes financiadores privados. Ela o faz, entretanto, sem abandonar a sua tradição universalista, procurando ressaltar o tema da eqüidade das políticas e práticas de saúde.

\section{A discussão do documento Etnicidade e Saúde na OPAS e o impacto dos Objetivos do Milênio}

Nos marcos de sua nova preocupação com a incorporação de componentes de seletividade/ eqüidade nas suas políticas de saúde, em 2003, no âmbito da Divisão de Saúde e Desenvolvimento Humano, tem início a elaboração do documento de trabalho Etnicidade e Saúde. Seu objetivo era “...encorajar a discussão entre os membros do Subcomitê de Planificação e Programação da Organização com respeito à incorporação da perspectiva étnico-racial na formulação de políticas públicas de saúde...” 25 (p. 3). Depois de revisado pelo Subcomitê, esse documento foi discutido na 132a Sessão do Comitê Executivo, realizada em junho do mesmo ano. Seu envio a esta instância decisória da OPAS reiterava a pertinência do debate, ressaltando a importância de uma maior eqüidade em saúde, que se expressaria nas políticas de redução da pobreza e implementação dos Objetivos do Desenvolvimento do Milênio. O Comitê Executivo foi instado a examinar o do- cumento Etnicidade e Saúde e a formular suas observações acerca de dois pontos principais: “a) a importância de incorporar a coleta da informação da saúde dos grupos étnicos; b) a necessidade de incorporar [um] a sensibilidade étnico-racial que contribua aos Objetivos de Desenvolvimento do Milênio com a perspectiva da redução da iniqüidade em saúde" 26 (p. 1). O Informe Final do Comitê Executivo ressaltou a importância do Plano Estratégico 2003-2007 e do documento Etnicidade e Saúde, afirmando que este último se constituía em uma importante contribuição para a compreensão geral da situação de indígenas e negros nas Américas, e para a formulação de políticas e programas focalizados nos grupos étnicos. Embora o Comitê não tenha julgado necessário adotar uma resolução específica acerca da temática, ficou acordado que: “...a OPAS daria apoio aos Estados Membros na desagregação das estatísticas nacionais e sanitárias para avaliar disparidades em saúde com fundamento étnico e monitorar o progresso rumo aos Objetivos de Desenvolvimento do Milênio. Deveria [ainda] apoiar a formulação de políticas de saúde com sensibilidade étnica que abordassem os determinantes discriminatórios dessas disparidades" 27 (p. 53-4).

Ainda que não tenha resultado em uma deliberação específica, a decisão do Comitê Executivo evidencia a importância que as questões étnico-raciais adquiriram na formulação de políticas de saúde por parte da OPAS. Como salienta César Vieira (1997, comunicação pessoal) - então membro do PPPS da Divisão de Saúde e Desenvolvimento Humano da OPAS - a própria discussão do documento Etnicidade e Saúde deu visibilidade a um assunto que jamais havia sido prioritário para a Organização. Dado o ineditismo do tema, sua presença nas atas e documentos já era em si um fato merecedor de destaque.

O Informe Final do Comitê Executivo destacou ainda a articulação entre políticas de saúde com enfoque étnico-racial e os Objetivos de Desenvolvimento do Milênio (ODMs). Tais objetivos foram elaborados com base nas ações e metas definidas pela Declaração do Milênio das Nações Unidas, adotada pelos 191 países-membros da ONU durante a Cúpula do Milênio, realizada em Nova York, Estados Unidos, em setembro de 2000. Previstos inicialmente para serem alcançados até o ano de 2015, os ODMs constituem oito objetivos que procuram responder aos principais desafios do desenvolvimento no mundo, definindo, assim, uma lista dos principais componentes da agenda global do século XXI. Vistos em seu conjunto, os ODMs sintetizam muitos dos compromissos acordados nas conferências internacionais realizadas nos anos 1990, e reconhecem 
explicitamente a interdependência entre crescimento econômico, redução da pobreza e desenvolvimento sustentável 27 .

Os ODMs forneceram à OPAS a oportunidade de reafirmar a saúde como um tema central na agenda do desenvolvimento mundial, uma vez que 3 dos 8 objetivos a serem atingidos referemse especificamente a temas deste setor, assim como 7 das 18 metas. O comprometimento cada vez maior da Organização com os ODMs fortaleceu a discussão sobre a adoção de políticas específicas voltadas para grupos étnicos. Em sua entrevista, César Vieira (1997, comunicação pessoal) comenta que a convocatória efetuada pelos ODMs conferiu à temática étnico-racial um peso muito maior do que o que seria dado por uma decisão "corporativa”, ou seja, estritamente infraorganizacional, ou mesmo do "setor" saúde.

A análise da documentação sinaliza, por outro lado, que o Subcomitê de Planificação e Programa procurou articular as demandas por questões étnico-raciais com aquelas relacionadas às questões de gênero 28,29, uma associação que foi, inclusive, materializada na reforma administrativa implementada na OPAS por Mirta Periago, eleita diretora da Organização em 2002, na qual foi criada uma nova área técnica: a Unidade de Gênero, Etnia e Saúde.

Após a discussão do documento Etnicidade e Saúde pelo Comitê Executivo em 2003, a temática étnico-racial ganhou um novo impulso na OPAS com a centralidade adquirida pelas discussões em torno dos ODMs. O consenso internacional em torno da necessidade de se alcançar tais objetivos reforçou a posição dos membros da OPAS que defendiam a adoção de um enfoque étnico-racial nos programas de saúde desenvolvidos pela Organização. Nesse novo cenário, contudo, a OPAS evita referenciar-se tanto à saúde indígena quanto à saúde da população negra, adotando cada vez mais freqüentemente o termo etnia ou, como no caso do documento citado anteriormente, "grupos excluídos historicamente", como uma designação mais geral que abarca estas duas populações. Por outro lado, a influência das questões de gênero sobre aquelas relacionadas à etnia torna-se cada vez maior, refletindo-se na nova estruturação da OPAS. Os efeitos desse novo quadro ficam claros quando analisamos as alterações feitas pelo Subcomitê de Planejamento e Programa no documento Los Objetivos de Desarrolo del Milenio y las Metas de Salud ${ }^{28}$, dentre as quais destaca-se a exclusão de menções diretas a "grupos autóctones" e "afro-descendentes americanos", preferindo a expressão mais geral "grupos excluídos historicamente", e a inclusão de "famílias chefiadas pela mulher" como um grupo específico que também compunha a chamada "nova pobreza" e que, por conseguinte, merecia a adoção de políticas específicas.

\section{Considerações finais}

O ambiente institucional em que ocorreram a formulação e as decisões em torno da adoção de políticas de saúde com enfoque étnico-racial na região das Américas caracterizava-se pela presença de um número cada vez maior de atores, com grande poder de agenda e de articulação. Dentre esses novos atores, destacam-se organismos multilaterais como o Banco Mundial e o BID, que desde o final da década de 1990 empreenderam esforços no sentido de consolidar uma nova orientação para as políticas de combate à pobreza na América Latina, articulando-as a estratégias antidiscriminação que atentassem para as especificidades étnico-raciais das populações da região. A temática da saúde da população negra emergiu nesse novo contexto como um componente das novas concepções que procuravam articular raça, etnia e saúde, embora, em um primeiro momento, estas estivessem sensivelmente ligadas ao tema da saúde das populações indígenas. Contudo, com a proximidade da Conferência de Durban e conforme conferências preparatórias foram sendo realizadas, os termos dessa relação seriam atualizados e a saúde da população negra ganhou destaque, envolvendo organizações que até então não haviam se ocupado do tema, como é o caso da OPAS.

Após a Conferência de Santiago de 2001, a OPAS se envolveu com essa temática fazendo valer a agenda estabelecida pelo Banco Mundial e o BID no encontro Race and Poverty. Nesse sentido, o poder de agenda desses organismos, somado à pressão dos movimentos sociais, foram decisivos para o envolvimento da OPAS com o tema. A discussão é iniciada em seus corpos diretores, tendo por base o ativismo, as formulações e a produção intelectual de Cristina Torres, que na ocasião compunha a equipe do Programa de Políticas Públicas em Saúde da OPAS.

Repercutindo os postulados estabelecidos ao final do encontro Race and Poverty de 2000, a OPAS deu início a uma série de documentos de referência, que teve como ápice a elaboração do documento Etnicidade e Saúde, cuja discussão no âmbito do Comitê Executivo da Organização atraiu a atenção para um tema que, a partir de então, tornou-se relevante e crescentemente associado aos Objetivos de Desenvolvimento do Milênio.

A articulação da temática étnico-racial com os ODMs fortaleceu o posicionamento daqueles 
que na OPAS defendiam um maior compromisso da Organização com políticas de enfoque étnicoracial. Diante desse fortalecimento e nos marcos de uma reforma na sua estrutura burocrática, as questões relacionadas à etnicidade foram agrupadas àquelas ligadas ao gênero - outro tema candente - em uma nova área temática: a Unidade Gênero, Etnia e Saúde. Com a criação dessa nova área, a OPAS visava a desenvolver políticas conjuntas para duas populações-alvo com forte apelo no cenário internacional - mulheres e grupos étnico-raciais específicos - como parte de estratégias orientadas à eqüidade em saúde.

A OPAS entra nesse terreno de posse de uma tradição anterior no campo da saúde das populações indígenas, que é atualizada e ressignificada no contexto dos preparativos para a Conferên- cia de Durban. Seu envolvimento com a temática étnico-racial nos fornece elementos para entendermos o duplo papel desempenhado por organizações intergovernamentais no novo cenário global: como atores sociais e arenas. Como um ator social importante no campo da saúde internacional, a OPAS produziu documentos, organizou e participou de fóruns internacionais sobre o tema, produzindo e disseminando valores e enunciados prescritivos. Como arena, a OPAS, assim como as demais organizações internacionais, mostrou-se permeável a interesses de origens variadas, registrando o que seria uma certa "porosidade", para usarmos uma expressão de César Vieira. Da mesma forma, sua burocracia interna procurou movimentar-se em sintonia com esses mesmos interesses.

\section{Resumo}

O artigo analisa o processo de formulação, legitimação $e$ implementação de uma política de recorte racial no âmbito da Organização Pan-Americana da Saúde (OPAS). O trabalho compreende a emergência do tema no interior da organização internacional, a dinâmica institucional em torno da questão e as propostas centradas na população negra na América Latina. Essas são abordadas com base nas interações estabelecidas entre a OPAS e um conjunto de agências intergovernamentais e organizações privadas com atuação relevante no domínio da saúde internacional. O envolvimento da OPAS com a temática étnico-racial fornece elementos para entendimento do duplo papel desempenhado por organizações intergovernamentais no novo cenário global: como atores sociais e arenas. Como ator social importante no campo da saúde internacional, a OPAS produziu e disseminou valores e enunciados prescritivos relacionados com a temática étnico-racial. Como arena, a organização mos trou-se permeável a interesses de origens variadas, com sua burocracia interna procurando movimentar-se em sintonia com os mesmos.

Organização Pan-Americana da Saúde; Agências Internacionais; Cooperação Internacional; Grupos Étnicos 


\section{Colaboradores}

Todos os autores participaram da concepção, análise, redação e revisão final do manuscrito.

\section{Agradecimentos}

Agradecemos a Ypuan Garcia pela pesquisa e organização das fontes documentais relativas à OPAS.

\section{Referências}

1. Finnemore M. National interests in international society. Ithaca: Cornell University Press; 1996.

2. Herz M, Hoffmann AR. Organizações internacionais: história e práticas. Rio de Janeiro: Elsevier; 2004.

3. Marques E. Notas críticas à literatura sobre Estado, políticas estatais e atores políticos. Revista Brasileira de Informação Bibliográfica em Ciências Sociais 1997; 43:67-102.

4. Escobar A. La invención del Tercer Mundo. Construcción y desconstrucción del desarrollo. Santa Fé de Bogotá: Editorial Norma; 1998.

5. Brown T, Cueto M, Fee E. A transição da saúde pública "internacional" para "global” e a Organização Mundial da Saúde. Hist Ciênc Saúde-Manguinhos 2006; 13:623-47.

6. Telles E. Race in another America: the significance of skin color in Brazil. Princeton: Princeton University Press; 2004.

7. Cueto M. O valor da saúde: história da Organização Pan-Americana da Saúde. Rio de Janeiro: Editora Fiocruz; 2007.

8. Vizentini PF. Relações internacionais do Brasil. De Vargas a Lula. Rio de Janeiro: Editora Fundação Perseu Abramo; 2005.

9. Silva GMD. Ações afirmativas no Brasil e na África do Sul. Tempo Social 2006; 18:131-65.

10. Torres C, Mújica OJ. Salud, equidad y los Objetivos de Desarrollo del Milenio. Rev Panam Salud Pública $2004 ; 15: 430-9$.
11. Htun M. From "racial democracy" to affirmative action: changing state policy on race in Brazil. Lat Am Res Rev 2004; 39:60-89.

12. Inter-American Dialogue. Race and poverty: interagency consultation on Afro-Latin Americans. Proceedings of the Roundtable. Washington DC: Inter-American Dialogue/Inter-American Development Bank/World Bank; 2000.

13. Pan American Health Organization. Health program of the indigenous peoples of the Americas. Action plan 2005-2007. Washington DC: Pan American Health Organization; 2004.

14. United Nations Preparatory Committee for the World Conference Against Racism, Racial Discrimination, Xenophobia and Related Intolerance. Reports of the Preparatory Meetings and Activities at the International, Regional and National Levels. Geneva: General Assembly of United Nations; 2001.

15. Torres C. La equidad en materia de salud vista con enfoque étnico. Rev Panam Salud Pública 2001; 10:188-201.

16. Vieira C. Apresentação. In: Organização Pan-Americana da Saúde, editor. Eqüidade em Saúde: uma visão pelo prisma da etnicidade. Washington DC: Organização Pan-Americana da Saúde; 2001. p. vi.

17. Organización Panamericana de la Salud/Organización Mundial de la Salud. Plan de acción sobre etinicidad y equidad en salud. Washington DC: Organización Panamericana de la Salud; 2001. 
18. World Health Organization/Pan American Health Organization. WHO/PAHO's contribution to the World Conference Against Racism, Racial Discrimination, Xenophobia and Related Intolerance: health and freedom from discrimination. Geneva: World Health Organization/Washington DC: Pan American Health Organization; 2001.

19. United Nations. Durban declaration and programme of action. Durban: United Nations; 2001.

20. Programa das Nações Unidas para o Desenvolvimento/Organização Pan-Americana da Saúde. Política nacional de saúde da população negra: uma questão de eqüidade. Brasília: Programa das Nações Unidas para o Desenvolvimento/Organização Pan-Americana da Saúde; 2002.

21. Maio MC, Monteiro S. Tempos de racialização: o caso da "saúde da população negra" no Brasil. Hist Ciênc Saúde-Manguinhos 2005; 12:419-46.

22. Fry PH. O significado da anemia falciforme no contexto da "política racial" do governo brasileiro 1995-2004. Hist Ciênc Saúde-Manguinhos 2005; 12:347-70.

23. Organização Pan-Americana da Saúde/Organização Mundial da Saúde Plano estratégico 2003-2007 da Repartição Sanitária Pan-Americana. CSP26/10 (Port.) de 15 de gosto de 2002. 26a Conferência Sanitária Pan-Americana - 54a Sessão do Comitê Regional. Washington DC: Organização Pan-Americana da Saúde/Organização Mundial da Saúde; 2002.

24. Pan American Heath Organization. Health in the Americas, 2002 edition. Washington DC: Pan American Heath Organization; 2002.
25. Pan American Health Organization/World Health Organization. Ethnicity and health. SPP37/10 (Eng.) 23 January 2003. 37th Session of the Subcommittee on Planning and Programming of the Executive Committee. Washington DC: Pan American Health Organization/World Health Organization; 2003.

26. Organización Panamericana de la Salud/Organización Mundial de la Salud. Grupo Étnico y Salud. CE132/16 (Esp.) 1 mayo 2003. 132a Sesión del Comité Ejecutivo. Washington DC: Organización Panamericana de la Salud/Organización Mundial de la Salud; 2003.

27. Organización Panamericana de la Salud/Organización Mundial de la Salud. Informe final. CE132/ FR (Esp.) 23 julio 2003. 132a Sesión del Comité Ejecutivo. Washington DC: Organización Panamericana de la Salud/Organización Mundial de la Salud; 2003.

28. Organización Panamericana de la Salud/Organización Mundial de la Salud. Los objetivos de desarrollo del milenio y las metas de salud. SPP38/4 (Esp.) 18 febrero 2004. 38a Sesión del Subcomité de Planificación y Programación del Comité Ejecutivo. Washington DC: Organización Panamericana de la Salud/Organización Mundial de la Salud; 2004.

29. Organização Pan-Americana da Saúde/Organização Mundial da Saúde. Objetivos de desenvolvimento do milênio e metas da saúde. CE134/10 (Port.) 24 de maio 2004. 134a Sessão do Comitê Executivo. Washington DC: Organização Pan-Americana da Saúde/Organização Mundial da Saúde; 2004.

Recebido em 09/Jul/2009

Aprovado em 01/Out/2009 